\title{
EDUCAÇÃO E SOCIEDADE: RELAÇÃO INTERATIVA
}

\author{
Adelcio Machado dos Santos ${ }^{1}$ \\ Universidade Alto Vale do Rio do Peixe. Caçador, Brasil \\ Everaldo da Silva \\ Universidade Alto Vale do Rio do Peixe. Caçador, Brasil \\ Joel Haroldo Baade \\ Universidade Alto Vale do Rio do Peixe. Caçador, Brasil
}

\begin{abstract}
Resumo. O ser humano é um ser social, e sua necessidade de organização tem por base a capacidade humana de conhecer e construir a compreensão acerca dos meios e dos processos fundamentais para a organização e a facilitação do ato de viver. O conhecimento é um produto da atividade consciente do pensamento que determina a natureza social do ser humano e o condiciona a sua história e a sua cultura. Face à incompletude humana, as instituições sociais, entre elas a instituição educacional, zelam pela inserção do indivíduo na vida em sociedade. Diante disso, a presente análise objetiva a compreensão e descrição do processo interativo e dialético que se estabelece entre educação e sociedade. Metodologicamente, a análise é de natureza básica, apoiada na pesquisa bibliográfica e na abordagem qualitativa. Conclui-se que, por meio da instituição educacional, estimula-se que o ser humano aprenda a conviver socialmente, apropriando-se da cultura, dos padrões de comportamento e do conhecimento produzido. A educação também exerce o controle social do comportamento humano. Evidencia-se, com isso, a profunda interatividade que há entre educação e sociedade. Cabe ao processo educativo exercer o papel social transformador, ao mesmo tempo em que se transforma em decorrência das mudanças na sociedade.
\end{abstract}

Palavras-chave: educação, sociedade, cultura, conhecimento, instituiç̃oes sociais.

\section{EDUCACIÓN Y SOCIEDAD: RELACIÓN INTERACTIVA}

Resumen. El ser humano es un ser social y su necesidad de organización se sostiene en la capacidad humana para conocer y construir la comprensión acerca de los medios y de los procesos fundamentales para la organización y la facilitación del acto de vivir. El conocimiento es un producto de la actividad consciente del pensamiento que determina la naturaleza social del ser humano y lo condiciona a su historia y a su cultura. Ante lo incompleto del ser humano, las instituciones sociales, entre ellas las instituciones educacionales, velan por la inserción del individuo en la vida en sociedad. Este es un análisis objetivo y comprensivo que describe el proceso interactivo y dialéctico que se establece entre educación y sociedad. Metodológicamente, el análisis es de naturaleza básica, con uso del método bibliográfico y abordaje cualitativo. Se concluyó que, por medio de la institución educacional, el ser humano es estimulado a convivir socialmente, apropiando la cultura, los patrones de comportamiento y el conocimiento producido. La educación también ejerce el control social del comportamiento humano. Se

\footnotetext{
1 Adelcio Machado dos Santos - Universidade Alto Vale do Rio do Peixe. Caçador, Brasil. Endereço: Rua Prof. Egidio Ferreira, $\mathrm{n}^{\circ}$ 271, Bloco “E”, Apto. 303 CEP: 88090-500, Florianópolis (SC) Brasil. E-mail: adelciomachado@ gmail.com.
} 
evidencia, con eso, la profunda interactividad que hay entre educación y sociedad. Compete al proceso educativo ejercer el rol social transformador, mientras también se transforma en función de los cambios sociales.

Palabras clave: Educación, Sociedad, Cultura, Conocimiento, Instituciones Sociales.

\title{
EDUCATION AND SOCIETY: INTERACTIVE RELATION
}

\begin{abstract}
The human being is a social being. Its need of organization is based on the human capacity of knowing and building comprehension regarding the means and basic processes for organizing and making its living easier. Knowledge is a product of conscious thinking activity, which determines the social nature of the human being, as well as influences its history and culture. Facing the fact that man is an incomplete being, the social institutions, among them the educational ones, care for the insertion of the individuals in society. This analysis aims to comprehend and describe the interactive and dialectic processes established between education and society. Methodologically, the analysis is from basic nature, with qualitative and descriptive approaches and it uses bibliographic sources. The conclusion in that, though educational institutions, the human being learns how to live in society, accepting its culture, behavior patterns and knowledge developed in it. Education also works as a social control of the human behavior. This way, we highlight that there is deep interactivity between education and society. The teaching process plays a transforming role in society, preparing the individuals for applying knowledge through the exercise of a transforming practice activity.
\end{abstract}

Keywords: Education, Society, Culture, Knowledge, Social Institutions.

\section{Introdução}

Sistematicamente, os indivíduos interagem socialmente. Esse processo tem na escola uma de suas bases iniciais e fundamentais de consolidação. É no entorno educacional que a interação se estende para além do restrito ambiente familiar, estimulando uma convivência mais direta com outros seres humanos, que influencia na incorporação de padrões de conduta, na apropriação de novos conhecimentos, no estabelecimento de relacionamentos mais extensivos e, oportunamente, na transformação da realidade. Nesse processo, todo o conhecimento acessado, apropriado, construído, socializado e difundido na instituição educacional e por ela tem por base a relação que há entre homem e sociedade.

As observações clássicas acerca dessa sociabilidade e a centralidade a ela conferida nos estudos das diferentes ciências humanas provam que a identidade humana é reconhecida e estabelecida ante um grupo. Em outras palavras, o ser humano só se faz como tal diante de outro, com o qual estabelece mecanismos diversos de interação constante. É essa interação, na origem, entre um número de indivíduos mais restrito, no 
final, entre grupos e sociedades inteiras, que define uma das características humanas fundamentais, qual seja, a da vida social, situação que define a importância da função social da escola.

Nóvoa (1998) lembra, contudo, que a história da escola foi confundida como a história do progresso, desconsiderando-se os avisos de Ortega e Gasset sobre o erro da vinculação exclusiva entre grandes nações e boas escolas. Para o autor, uma grande nação depende de boas escolas, mas também da economia, da política, da justiça, da saúde, entre outros aspectos. Nesse ínterim, o reforço da ligação entre os vértices professores-Estado, provocado pela ideia da escola como redentora da humanidade, conduziu à marginalização as famílias-comunidades e, portanto, da sociedade em sua amplitude.

Em contrapartida, a educação exerce influência sobre a sociedade e é influenciada por ela. Reside nessa capacidade de transformação recíproca a crítica de Frigotto (1999) quanto à perspectiva de limitar a função social da educação à sua capacidade de responder as demandas do capital.

Nessa condição se infere a preocupação deste estudo com a relação entre educação e sociedade, reforçando o pensamento de Nóvoa (1998) sobre a necessidade de repensar a escola, trazendo para o seu cenário o vértice perdido, ou seja, a sociedade. Parte-se do princípio que o ser humano possui uma natureza social e que a escola pode colaborar para ampliar esse processo, desde que não mantenha suas práticas à margem das demandas sociais, políticas, econômicas, culturais e ambientais.

Especificamente no Ensino Superior, essa interação é uma condição favorecida pela articulação entre o ensino, a pesquisa e a extensão. Prevista na Lei de Diretrizes e Bases da Educação Nacional, Lei n. 9.394 (1996), essa indissociabilidade entre os três âmbitos é acentuada nas indicações de Calderón, Pedro e Vargas (2011) quando propõem o amadurecimento teórico no sentido de não restringir a responsabilidade social do Ensino Superior à extensão, tampouco manter as práticas pedagógica nos cativeiros disciplinares, conforme destaca Zwierewicz (2013a).

Indicações como as da curricularização da extensão, prevista no Plano Nacional de Educação (PNE), documento em que se propõe que se assegure, minimamente "[...] dez por cento do total de créditos curriculares exigidos para a graduação em programas e projetos de extensão universitária, orientando sua ação, prioritariamente, para áreas de grande pertinência social.” (Brasil, 2014, p. 72), são condições essenciais para a interação entre educação e sociedade. De outra forma, mudanças nas práticas pedagógicas, priorizando perspectivas mais interdisciplinares e transdisciplinares, contribuem para superar uma educação isolada da realidade social.

$\mathrm{Na}$ interação entre Ensino Superior e sociedade, estimulada pelo tripé ensinopesquisa-extensão, reside uma das possibilidades para superar a função restrita das Instituições de Ensino Superior (IES) como “... transmissoras de conhecimentos científicos precedentes para se posicionarem como entornos de acesso, discussão, 
produção e difusão de conhecimentos que colaborem para o atendimento de demandas dos entornos nos quais se inserem." (Willemann e outros, 2015, p. 513). Contudo, essa interação não ocorre da mesma forma na Educação Básica, já que as práticas que efetiva não têm se respaldado no ensino, distanciando as escolas da pesquisa e mais amplamente da extensão. Decorre dessa condição a necessidade de fortalecer ações que viabilizem a interação com a sociedade, evitando que sigam formando pessoas com a preocupação exclusiva de preparação para o mercado de trabalho.

A iniciativa prevista na avaliação da Educação Básica, realizada pelo Instituto Nacional de Estudos e Pesquisas Educacionais Anísio Teixeira (INEP), e que implica na elaboração de provas compostas por questões contextualizadas, indica, minimamente, que a Educação Básica também precisa superar o paradigma tradicional, centrado na transmissão e na memorização de conhecimentos, para transitar por um paradigma mais emergente (Zwierewicz e outros, 2015).

Nesse processo, perdem sentido os espaços institucionais que mantêm os estudantes imobilizados “... por horas intermináveis, ouvindo um professor após outro falar e escrever sobre coisas mortas, conhecimentos construídos por outros, ideias totalmente fora do contexto em que estão inseridos, sem relação com suas vidas, seus trabalhos, suas famílias, seus desejos ... (Rosa, Basso e Borges, 2009, p. 19). Também perde sentido o docente caracterizado como um "[..]intérprete mascarado pela retórica, apoiado no que leu e no que sua experiência lhe outorga a partir de sua vivência laboral ou simples titulação universitária, com pensamento unidirecional, reducionista e mecanicista.” (González Velasco, 2012, p. 87).

Para dinamização de novas possibilidades educacionais no sentido de ampliar a interação entre educação, independentemente de ser básica ou superior, contribuem autores como Mallart (2009), Moraes (1997, 2004), Morin (2001, 2007, 2009, 2011, 2014a, 2014b), Nicolescu (2005, 2014), Pineau (2000, 2014), Pinho, M. V. R. Suanno e J. H. Suanno (2015), Santos (2009), Silva (2008), Sommerman, Mello e Barros (2002), Torre (2012, 2013), Torre e Zwierewicz (2009), Zwierewicz (2013a, 2013b), entre outros. São autores como esses que têm possibilitado transitar entre perspectivas teóricas atentas às demandas contemporâneas e às incertezas em relação ao futuro e iniciativas práticas que colaboram para transformar a escola e a realidade.

Com base nessas reflexões, esta pesquisa analisou, brevemente, aspectos relacionados à interatividade entre educação e sociedade, cuja relação é estudada, principalmente, pela Sociologia da Educação, que é uma área específica dentro da Sociologia, responsável pelo estudo da relação da sociedade e dos aspectos desta com a educação. Nessa análise, a pesquisa pautou-se nos seguintes objetivos específicos: a) situar na organização social características que constituem seus membros e os aproximam em função de necessidades e expectativas, entre as quais situam-se as destacadas por Morrish (1977); b) situar a cultura na definição de padrões e formações sociais, considerando que o processo civilizador é vinculado à formação de grupos que 
conhecem, registram e compartilham o produto de sua atividade pensante; c) discutir a elaboração de conhecimento a partir da perspectiva de sua constituição como produto da atividade consciente do pensamento que determina a natureza social do ser humano e o vincula a sua história e a sua cultura, processo que é pressuposto para Vasconcellos (2002); d) a capacidade dos sujeitos de captar a estrutura objetiva do real e representá-la subjetivamente; e) situar a educação como processo social, tendo em vista que, para Vasconcellos (2002), seu papel é transformar o simples conhecimento em um saber social, visto que a teoria em si não transforma o mundo.

Para realização da pesquisa optou-se pela análise bibliográfica, apoiada na abordagem qualitativa. Essa definição metodológica oportunizou o acesso a estudos precedentes vinculados à temática, proporcionado o alcance dos objetivos propostos na pesquisa. Espera-se que seus resultados fortaleçam a valorização da interação entre a universidade e sociedade, processo favorecido pela indissociabilidade entre ensino, pesquisa e extensão.

\section{Método}

No que concerne à caracterização ao tipo de estudo, foi adotada pesquisa bibliográfica, que "... implica em um conjunto ordenado de procedimentos de busca por soluções, atento ao objeto de estudo, e que, por isso, não pode ser aleatório." (Lima e Mioto, 2007, p. 37). Essa opção se ampara nas contribuições de Minayo (1994) ao defender que a seleção metodológica implica a definição de percursos que colaboram para a compreensão de determinada realidade e da posição humana em relação a esse processo.

Independentemente do tipo de estudo, a pesquisa bibliográfica é necessária para sustentar os resultados a partir da comparação com estudos precedentes. Contudo, neste caso, engloba o exame das produções registradas em livros, artigos e outros documentos para que seja realizado o levantamento e a análise do que já foi produzido acerca do objeto pesquisado, conforme defende Gil (1997).

Ressalta-se que, de acordo com Lakatos e Marconi (1992), a pesquisa bibliográfica possibilita não apenas a solução de problemas já conhecidos no meio científico, mas também a exploração de novas áreas, caracterizadas por problemas que ainda não foram totalmente explorados e esclarecidos, como é a pretensão do presente estudo. Nesse sentido, o levantamento bibliográfico não é uma simples repetição do que já foi dito ou escrito sobre determinado assunto, uma vez que permite o exame de um tema sob novo enfoque ou abordagem, chegando a novas conclusões.

Quanto à abordagem, optou-se pela qualitativa, por meio da qual se busca a compreensão de fenômenos da realidade, dos seus significados, trabalhando com valores, atitudes, motivações, entre outros que não podem ser quantificados. No juízo de Haguette (1997) a pesquisa qualitativa destaca as especificidades de um fenômeno no que diz respeito às suas origens e razões de ser, proporcionando uma compreensão mais profunda de determinado fenômeno. 
Amparando o estudo bibliográfico, a abordagem qualitativa possibilitou analisar subjetivamente, nos estudos precedentes, quatro categorias: sociedade, cultura, conhecimento e educação. A análise se sustentou pela perspectiva da articulação existente essencialmente entre a primeira e a última categoria elencada.

\section{Resultados e discussão}

Considerando os objetivos da pesquisa, os resultados são situações em quatro eixos, envolvendo a organização social e a definição de características que se articulam na sua formação, o potencial da cultura na definição de padrões e formações sociais, o processo de elaboração do conhecimento e o papel da educação na transformação do conhecimento em um saber social.

\section{- Organização Social: características da sociedade humana}

A necessidade da vida social, ou seja, da organização social do homem, tem por base a capacidade humana de conhecer, de construir a compreensão sobre os meios e os processos fundamentais para a organização e a facilitação do ato de viver (Ferreira, 2001).

Desde os primórdios das cavernas, o homem percebeu que, ao agir sozinho perante as forças da natureza, limitaria suas condições de sobrevivência. Destarte, surgiram os bandos e os clãs, a partir da percepção natural da necessidade do uso da força coletiva, única maneira que pudesse assegurar a proteção de cada um dos desafios impostos pelo meio ambiente.

$\mathrm{Na}$ medida em que os desafios eram superados, reforçava-se a necessidade de organizar-se socialmente, convivendo em grupo e desenvolvendo os processos organizadores que agregavam os grupos em torno das facilidades conquistadas para o viver cotidiano.

A capacidade de conhecer desenvolveu a vida social, e essa vida grupal, por sua vez, ampliou o próprio conhecimento humano, evidenciando a constante interatividade entre desenvolvimento do conhecimento e sociedade. Esse processo civilizador estendeu-se por milênios, chegando à sociedade atual, com uma organização social extremamente complexa, formada de diferentes instituições sociais.

As pessoas sociais possuem características em comum, ou seja, necessidades que precisam ser satisfeitas como uma condição de sobrevivência e de ajustamento a sua condição de ser social. Pessoa (2001) destaca que, entre as inúmeras necessidades sociais, algumas são consideradas universais, sendo compartilhadas pelas pessoas de todas as sociedades. Essas necessidades, como por exemplo a de alimentação, precisam ser satisfeitas para que as pessoas tenham uma existência compatível ao seu ambiente social. 
No intento de satisfazer qualquer uma das necessidades universais, os indivíduos seguem certos comportamentos padronizados e compartilhados pelos membros da sociedade. A constituição desses comportamentos caracteriza uma sociedade e segue alguns pressupostos enunciados por Morrish (1977):

- tomar as necessárias providências para manter relações adequadas com o meio;

- proporcionar uma adequada diferenciação de papéis;

- proporcionar um meio de comunicação para os seus membros;

- propiciar orientações e experiências cognitivas compartilhadas;

- estabelecer um conjunto compartilhado e articulado de metas;

- prescrever a regulamentação normativa de meios para a realização das metas;

- regular a expressão afetiva;

- socializar.

Por conseguinte, a sociedade compreende um conjunto permanente de pessoas, conjunto esse caracterizado por determinados fins e determinadas relações que ligam seus componentes. Por toda parte, sustenta Saldanha (1972, os homens vivem em sociedade e formam diferentes culturas, devido ao aspecto peculiar que sua vida toma.

\section{- Cultura, padrões e formações sociais}

Como resultado da organização social, destaca-se a caracterização da sociedade humana por meio da cultura. Ferreira (2001) registra que todo o processo civilizador somente poderia ocorrer em grupo, em sociedade, e seu produto é o que recebe o nome de cultura. Ao conhecer, registrar, compartilhar o produto de sua atividade pensante, o homem cria a cultura.

Para o autor citado, existe um longo fio processual que foi tecido pela capacidade cognitiva humana ao longo da História, a unir, em uma totalidade repleta de sentido, as naves espaciais controladas por redes computacionais à primeira roda que girou sob as mãos de um homem das cavernas (Ferreira, 2001).

O homem é, acima de tudo, um ser social que, no exercício dessa sua característica, desenvolve sua cultura, os padrões e as instituições sociais. Dessa forma, a cultura está situada entre os elementos que o ser humano adquire na vida social, visto que não a recebe por meio da herança genética.

A cultura é conceituada por Pessoa (2001) como o complexo que inclui os padrões de comportamento, as ideias e os objetos, tendo objetividade, ou seja, não existe em si mesma e não é um mero produto da imaginação humana. Ao transmitir o conhecimento do acervo cultural, a geração mais velha acaba por exercer certo poder coercitivo, uma vez que existe uma pressão social sobre a geração mais jovem para que adquira a cultura.

Nas sociedades, o processo de interiorizar a cultura alcança alguns objetivos: 
- manter a unidade social, condição necessária para a sua sobrevivência, pois essa unidade se deve em grande parte à cultura comum peculiar a cada sociedade.

- garantir à sociedade, por meio da transmissão da experiência social, a sua continuidade social, ou seja, a sua unidade social na perspectiva do tempo. Cada geração atua como elemento de ligação entre a geração anterior e a futura geração.

- contribuir para a evolução social ao se transmitir a cultura, à medida que se adapta a pessoa social às mudanças socioculturais, tornando-a aberta a essas transformações.

Nesse sentido, Swift (1977) afirma que a cultura não é somente alguma coisa que o homem faz, mas também, algo que o faz. A cultura estabelece essencialmente modelos de conduta, ou seja, padrões de comportamento assimilados pelas instituições sociais.

Uma formação social compreende um conjunto de padrões de comportamento compartilhados pela sociedade e orientados para a satisfação das necessidades do grupo. Dessa maneira, é possível inferir, segundo Pessoa (2001), que as instituições sociais principais são aquelas que se referem aos padrões de comportamento, orientando as pessoas na satisfação das suas necessidades sociais básicas.

As precípuas formações sociais são: a familiar, a educativa, a econômica, a política, a religiosa e a recreativa. Dentro do âmbito social, essas instituições, entre outras secundárias, não podem ser entendidas como atuando de modo isolado, mas, ao contrário, elas são interinfluentes.

A instituição não se reduz aos indivíduos: ultrapassa a simples reunião de pessoas, possibilitando uma interação. Assim, tomando-se a instituição educacional, é possível observar que ela exerce influência sobre as demais e, ao mesmo tempo, recebe delas muita influência.

Para Pessoa (2001), a escola representa uma instituição social de importância fundamental na convivência do homem em sociedade, por conta da sua crescente influência na socialização das novas gerações. Ne sentido, o processo de integração entre as diversas instituições dentro de um determinado sistema social é denominado de rede institucional da sociedade.

Outro aspecto que pode ser ressaltado, em relação às instituições sociais, referese ao fato de que essas instituições não possuem o mesmo ritmo de mudança social. A título de exemplo, pode-se tomar as instituições religiosas, as quais se modificam por meio de um processo muito lento; já as instituições econômicas, em virtude das inovações tecnológicas, possuem um ritmo de mudança social muito rápido. Isso acaba por provocar uma defasagem sociocultural que equivale à diferença do avanço nesse nível entre duas instituições. 
Ainda em relação às instituições sociais, Neto (1977) as classifica em regulativas e operativas. As regulativas (primárias) são aquelas cujas funções têm importância vital para a sociedade, controlando certos setores do comportamento dos indivíduos. As operativas (secundárias) são as instituiçõoes às quais se atribuem funções restritas, que interessam a certos grupos, em um determinado tempo, dentro de uma sociedade.

Essa abordagem institucionalista permite chegar a uma tipologia das sociedades, através da distinção das formas diferentes de uma ou várias das suas instituições principais.

\section{- Elaboração de conhecimento e saberes}

A condição humana é caracterizada pela capacidade de conhecer, de construir a compreensão sobre os meios e os processos essenciais para a organização e facilitação do ato de viver. O conhecimento constitui um produto da atividade consciente do pensamento que determina a natureza social do ser humano e o condiciona a sua história e a sua cultura.

É uma necessidade humana das mais importantes compreender a forma como se dá o conhecimento, pois é por meio dessa compreensão que a sociedade humana tem a possibilidade de avançar em seu processo de civilização.

Para que essa compreensão seja viável, de acordo com Ferreira (2001), faz-se necessário o questionamento permanente acerca da natureza das forças cognitivas humanas, sobre o próprio conhecimento e o processo através do qual o ser humano constrói o pensar. À medida que desvenda o processo mediante o qual obtém o conhecimento do mundo, o homem percebe a si mesmo como ente integrado na realidade.

A consciência humana não é somente um campo meramente subjetivo e apartado do mundo real; ela é o palco no qual a percepção e o conceito, como dois aspectos complementares, confrontam-se constituindo a realidade. $\mathrm{O}$ ato do conhecimento se revela como participação autoconsciente da realidade, a partir do momento em que este ato se torna consciente de si mesmo (Greuel, 1998 apud Ferreira, 2001). Essa consciência só é adquirida por meio da integração social, em que o homem passa a se apropriar do conhecimento e, posteriormente, produzi-lo.

Nesse sentido, Vasconcellos (2002) sustenta que, pelo conhecimento, o sujeito capta a estrutura objetiva do real e a representa subjetivamente. Essa representação pode se transformar em um instrumento de liberdade, em um meio para criar uma nova forma ético-política como fonte de novas iniciativas. Um conhecimento, para conduzir a ação, deve ser carregado de significado (compreensão) e de afetividade (envolvimento emocional).

Para Vasconcellos (2002), é necessário que o trabalho com o conhecimento esteja articulado com a realidade no sentido de buscar obter sua transformação. É certo 
que nem todo conhecimento possibilita uma articulação prática imediata, mas é importante que, mesmo por mediações, seja assegurado seu vínculo com a transformação da realidade, papel este a ser exercido pela educação.

\section{- Educação como processo social}

Sob o ponto de vista sociológico, a educação compreende uma ação exercida, ou seja, uma atividade desenvolvida no meio social, por meio da qual a geração adulta pretende transmitir o seu patrimônio cultural, a sua herança social às gerações mais jovens. Ela se deve ao fato de que em cada organismo são considerados dois seres: um individual e outro social. O ser individual é aquele dado por meio da herança biológica fornecida pelos próprios pais, por meio do processo de hereditariedade.

O ser social, por sua vez, é formado de um sistema de ideias, sentimentos, hábitos dos grupos sociais de que cada organismo faz parte e ao qual se integra, especialmente, através do processo educacional. Os seres humanos não nascem sociabilizados, mas ao longo de suas vidas, principalmente, por meio do processo de educação, vão aprendendo a interagir socialmente (Oliveira, 1990).

À medida que o tempo passa, em decorrência do progresso tecnológico, muitos traços culturais são acrescidos à cultura e alguns podem cair em desuso, por se tornarem ultrapassados. A cultura de um povo não permanece sempre igual. Ela é modificada com o tempo, através das transformações que as novas gerações vão efetuando.

A educação exerce função socializadora, ao formar um ser social em cada um. Exerce, também, a função de controle social, ao ajustar os educandos aos padrões culturais vigentes, aos modelos de comportamento social, tornando-os capazes de se integrar na sociedade de uma forma adequada ao desenvolvimento da cultura, podendo ser conservadora ou inovadora.

A educação é, assim, ainda uma técnica social, podendo ser utilizada como fator conservador, de manutenção da ordem social, ou como fator construtivo de transformação consciente e intencional da ordem social vigente, ou seja, como fator de mudança social. Em outras palavras, a educação é utilizada como técnica social, isto é, como método de influenciar o comportamento humano, de forma que esse se enquadre nos padrões vigentes de interação e organização sociais.

De acordo com Vasconcellos (2002), a educação formal deve transformar o simples conhecimento em um saber social, visto que a teoria em si não transforma o mundo. O ponto de chegada da educação é a própria prática social, que permeia também o desenvolvimento e o fechamento de um processo educativo.

O conhecimento teórico em si não pode transformar o mundo, pode até contribuir para sua modificação, mas, para tanto, deve sair de si mesmo e, em primeiro lugar, necessita ser apropriado por aqueles que serão responsáveis por provocar os atos reais, efetivos, ou seja, a própria transformação. 
Entre o conhecimento teórico e a atividade prática transformadora, está incutido um trabalho de educação das consciências, de organização dos instrumentos materiais e planos concretos de ação. Conforme Vasconcellos (2002), a educação coloca-se justamente nessa tarefa de educação das consciências, constituindo-se uma maneira de mediar o processo de transformação objetiva da realidade.

Sob essa perspectiva, o processo educacional não transforma de forma direta e imediata a realidade social, mas de modo indireto, ou seja, agindo sobre os sujeitos da futura prática, como sustenta Saviani (1983 apud Vasconcellos, 2002). Destarte, como a educação exerce um papel mediador que tem reflexos profundos no meio social, é importante ater-se à forma como se desenvolve a educação e quais conteúdos nela são repassados.

Por ser um processo social, o que deve determinar a organização da educação e a construção do seu currículo é o objetivo de interferência na prática, com a finalidade de atuar na sua transformação, o que significa dizer que, de modo geral, todos os conteúdos devem estar voltados para a apropriação crítica da realidade, possibilitando a superação da dicotomia entre sala de aula e mundo social.

Em suma, a educação é um processo social que tem a finalidade de suscitar e desenvolver as potencialidades do indivíduo. A educação não se limita a desenvolver a natureza biológica e psíquica, o "eu" individual do homem, conforme afirma Oliveira (1990). A educação cria um ser novo - o ser social -, permitindo-lhe o desenvolvimento das qualidades físicas, intelectuais e morais, entre outras, formando um ser humano completo, apto ao convívio social.

\section{Conclusões}

Embora existam diferentes direcionamentos teóricos na Sociologia, é consenso que o homem se constitui um ser social. Ao longo do desenvolvimento das civilizações, o homem sempre procurou organizar-se cada vez mais em sociedade para garantir sua sobrevivência.

O homem, contudo, não nasce um ser social pronto. Ao contrário, é através da transmissão de padrões de comportamento, da apropriação da cultura, das características da organização humana e da interação com a sociedade que o indivíduo torna-se um ser social.

A sociedade atual, em sua complexidade, é caracterizada pela presença de diferentes instituições sociais, cuja função, entre outras, é de fortalecer a socialização entre as pessoas. Essas instituições, embora possuam características peculiares, não existem de forma isolada, mas estabelecem uma relação de troca de influências. Nesse sentido, a entidade educacional é uma das mais importantes instituições sociais; ela interage diretamente com a sociedade e suas demais organizações, influenciando e se deixando influenciar por elas. 
Destarte, evidencia-se a profunda interatividade entre educação e sociedade. A educação só existe para ensinar o homem a conviver socialmente, transmitindo e transformando a cultura, os padrões de comportamento, o conhecimento produzido, enfim, ela é um mecanismo de socialização. Ao mesmo tempo em que a educação socializa o homem, ela exerce o controle social do comportamento humano.

A educação, por meio da transmissão, produção e difusão do conhecimento, deve exercer o papel social transformador. O processo educativo deve exercer o papel de mediador no âmbito das transformações sociais, possibilitando a apropriação do conhecimento teórico e a educação da consciência humana, preparando para o convívio social e para a aplicação do conhecimento por meio do exercício da atividade prática transformadora.

\section{Referências}

Brasil. Lei n. 9.394, de 20 de dezembro de 1996 (1996). Estabelece as diretrizes e bases da educação nacional. Brasília. 1996. Recuperado de http://www.planalto.gov.br/ccivil_03/Leis/L9394.htm, em 10 de janeiro de 2016.

Brasil. Lei n. 13.005, de 25 de junho de 2014 (2014). Aprova o Plano Nacional de Educação - PNE e dá outras providências. Brasília. 2014. Recuperado de http://www.planalto.gov.br/ccivil_03/_ato2011-2014/2014/lei/113005.htm, em 10 de janeiro de 2016.

Calderón, A. I., Pedro, R. F. e Vargas, M. C. (2011, out./dez.). Responsabilidade social da Educação Superior: a metamorfose do discurso da UNESCO em foco. Interface: Comunicação, Saúde e Educação, 15(39).1185-98. Recuperado de http://www.scielo.br/scielo.php?pid= S141432832011000400017\&script=sci_arttext, em 27 de agosto de 2015.

Ferreira, D. (2001). Manual de Sociologia: dos clássicos à sociedade da informação. São Paulo: Atlas.

Frigotto, G. (1999). A produtividade da escola improdutiva (5a. ed.). São Paulo: Cortez.

Gil, A. C. (1997). Metodologia do ensino superior. São Paulo: Atlas.

González Velasco, J. M. (2012). Aplicações educativas da teoria transcomplexa. In S. Torre, M. Zwierewicz e E. C. Furlanetto (Org.). Formação docente e pesquisa transdisciplinar: criar e inovar com outra consciência. (pp. 75-98). Blumenau: Nova Letra.

Haguette, T. M. F. (1997). Metodologias qualitativas na sociologia. (5a. ed.). Petrópolis: Vozes.

Lakatos, E. M. E. e Marconi, M. A. (1992). Metodologia do trabalho científico (4a. ed. rev. e ampl.). São Paulo: Atlas.

Lima, T. C. S. e Mioto, R. C. T. (2007). Procedimentos metodológicos na construção do conhecimento científico: a pesquisa bibliográfica. Katal, 10(n. esp.), 37-45. 
Recuperado de http://www.scielo.br/pdf/rk/v10nspe/a0410spe, em 27 de outubro de 2015.

Mallart, J. (2009). Ecoformação para a escola do século XXI. In M. Zwierewicz e S. Torre (Org.). Uma escola para o século XXI: Escolas Criativas e resiliência na educação. (pp. 29-42). Florianópolis: Insular.

Minayo, M. C. S. (Org.). (1994). Pesquisa social: teoria método e criatividade. 17ª ed. Petrópolis, RJ: Vozes.

Moraes, M. C. (2004). Além da aprendizagem: um paradigma para a vida. In M. C. Moraes e S. Torre (Org.). Sentipensar: fundamentos e estratégias para reencantar a educação. (pp. 19-25). Petrópolis: Vozes.

Moraes, M. C. (1997). O paradigma educacional emergente (9a. ed.). Campinas: Papirus.

Morin, E. (2011). La vía: para el futuro de la humanidad. Barcelona: Paidós.

Morin, E. (2001). Os sete saberes necessários à educação do futuro (3a. ed.). São Paulo: Cortez; Brasília: UNESCO.

Morin, E. (2014b). Pour une politique de la villeau XXIème siècle: Contributionau 7ème Forum Urbain Mondial - Carta Medellín - WUF7 - 2014. Medellín: Fórum Urbano Mundial.

Morin, E. (2009). A cabeça bem-feita: repensar a reforma, reformar o pensamento (16a. ed.). Tradução de Elá Jacobina. Rio de Janeiro: Bertrand Brasil.

Morin, E. (2014a). Enseigner à vivre: manifeste pour changer l'éducation. Paris: Actes Sud.

Morin, E. (2007). Introdução ao pensamento complexo (3a. ed.). Porto Alegre: Sulina.

Morrish, I. (1977). Sociologia da Educação (3a. ed.). Rio de Janeiro: Zahar.

Neto, A. D. (1977). Sociologia Aplicada à Educação (2a. ed.). São Paulo: Duas Cidades.

Nicolescu, B. (2005). O Manifesto da Transdisciplinaridade. Tradução de Lucia Pereira de Souza (3a. ed.). São Paulo: TRIOM, 2005.

Nicolescu, B. (2014). Transdisciplinariedad: passado, presente y futuro. In A. C. Martinez e P. Galvani (Org.). Transdisciplinariedad y formación universitaria: teorías y prácticas emergentes. (pp. 45-90). Puerto Vallarta: CEUArkos.

Nóvoa, António. (1998). Relação escola-sociedade: novas respostas para um velho problema. In R. Volpato e outros (Org.). Formação de professores. (pp. 19-39). São Paulo: Edunesp.

Oliveira, P. S. (1990). Introdução à Sociologia da Educação. São Paulo: Ática.

Pessoa, X. C. (2001). Sociologia da Educação. Campinas: Alínea. 
Pineau, G. (2000). Temporalités en formation, vers de nouveaux synchroniseurs. Paris: Anthropos.

Pineau, G. (2014). Las reflexiones sobre las prácticas: el corazón de la vuelta reflexiva. In A. C. Martinez e P. Galvani (Org.). Transdisciplinariedad y formación universitaria: teorías y prácticas emergentes. (pp. 91-114). Puerto Vallarta: CEUArkos.

Pinho, M. J., Suanno, M. V. R. e Suanno, J. H. (Org.). (2015). Projetos criativos na prática pedagógica: cantar e encantar a aprendizagem. Goiânia: Espaço acadêmico.

Rosa, J. B. Basso, N. R. S. e Borges, R. M. R. (2007). Transdisciplinaridade: a natureza íntima da educação científica. Porto Alegre: Edipucrs.

Saldanha, N. N. (1972). Sociologia da Educação. Rio de Janeiro: Aurora.

Santos, Akiko. (2009). Complexidade e transdisciplinaridade em educação: cinco princípios para resgatar o elo perdido. In A. Santos e A. Sommerman. Complexidade e transdisciplinaridade: em busca da totalidade perdida. (pp. 1538). Porto Alegre: Sulina.

Silva, A. T. R. (2008, jul./dez.). Ecoformação: reflexões para uma pedagogia ambiental, a partir de Rousseau, Morin e Pineau. Desenvolvimento e Meio Ambiente, Curitiba, UFPR, 18, 95-104.

Sommerman, A., Mello, M. F. e Barros, V. M. (Org.) (2002). Educação e Transdisciplinaridade. São Paulo: Triom.

Swift, D. F. (1977). A Sociologia da Educação. São Paulo: Atlas.

Torre, S. (2013). Movimento de escolas criativas: fazendo parte da história de formação e transformação. In M. Zwierewicz (Org.). Criatividade e inovação no Ensino Superior: experiências latino-americanas em foco. (pp. 139-163). Blumenau: Nova Letra.

Torre, S. (2012). Criadores na adversidade e na crise: qual é o segredo? In S. Torre e M. Zwierewicz (Org.). Criatividade na adversidade: personagens que transformaram situações adversas em oportunidade. (pp. 19-48). Blumenau: Nova Letra.

Torre, S. e Zwierewicz, M. (2009). Projetos Criativos Ecoformadores. In M. Zwierewicz e S. Torre (Org.). Uma escola para o século XXI: escolas criativas e resiliência na educação. (pp. 153-176). Florianópolis: Insular.

Vasconcellos, C. S. (2002). Construção do Conhecimento em Sala de Aula (13a. ed.). São Paulo: Libertad.

Willemann, E. e outros. (2015). A responsabilidade social de instituições comunitárias de ensino superior (ices) e a curricularização da extensão: percursos e desafios do Unibave. Anais do SEMPEX. Orleans: Unibave, 5. (pp. 512-519).

Zwierewicz, M. e outros. (2015). Implicações das Escolas Criativas e dos projetos criativos ecoformadores no Programa de Formação-Ação de Docentes da Educação Básica e do Ensino Superior. Anais do SEMPEX. Orleans: Unibave, 5. (pp. 591-596). 
Zwierewicz, M. (2013). Apresentação. In M. Zwierewicz (Org.) Criatividade $e$ inovação no Ensino Superior: experiências latino-americanas e europeias em foco. (pp. 9-17). Blumenau: Nova Letra.

Zwierewicz, M. (2009). Escolas Criativas: escolas que aprendem, criam e inovam. In M. Zwierewicz e S. Torre (Org.). Uma escola para o século XXI: escolas criativas e resiliência na educação. (pp. 55-70). Florianópolis: Insular, 2009.

Zwierewicz, M. (2013a). Movimento de Escolas Criativas: fazendo parte da história de formação e transformação. In M. Zwierewicz (Org.). Criatividade e inovação no Ensino Superior: experiências latino-americanas em foco. (pp. 139-162). Blumenau: Nova Letra.

Data de recepção: 27/06/2015

Data de revisão: 08/12/2015

Data do aceite: 18/12/2015 
Santos, A. M.; Silva, E. e Baade, J. H. 